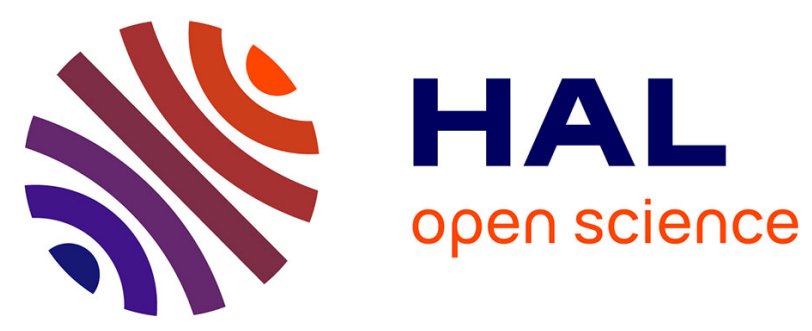

\title{
A Phenyl-Pyrrolidine Derivative Reveals a Dual Inhibition Mechanism of Myocardial Mitochondrial Permeability Transition Pore, Which Is Limited by Its Myocardial Distribution
}

\author{
Mathieu Panel, Abdelhakim Ahmed-Belkacem, Isaac Ruiz, Jean-François \\ Guichou, Jean-Michel Pawlotsky, Bijan Ghaleh, Didier Morin
}

\section{To cite this version:}

Mathieu Panel, Abdelhakim Ahmed-Belkacem, Isaac Ruiz, Jean-François Guichou, Jean-Michel Pawlotsky, et al.. A Phenyl-Pyrrolidine Derivative Reveals a Dual Inhibition Mechanism of Myocardial Mitochondrial Permeability Transition Pore, Which Is Limited by Its Myocardial Distribution. Journal of Pharmacology and Experimental Therapeutics, 2021, 376 (3), pp.348-357. 10.1124/jpet.120.000359 . hal-03155967

\section{HAL Id: hal-03155967 https://hal.science/hal-03155967}

Submitted on 2 Mar 2021

HAL is a multi-disciplinary open access archive for the deposit and dissemination of scientific research documents, whether they are published or not. The documents may come from teaching and research institutions in France or abroad, or from public or private research centers.
L'archive ouverte pluridisciplinaire HAL, est destinée au dépôt et à la diffusion de documents scientifiques de niveau recherche, publiés ou non, émanant des établissements d'enseignement et de recherche français ou étrangers, des laboratoires publics ou privés. 


\section{Title page}

\section{A phenyl pyrrolidine derivative reveals a dual inhibition mechanism of myocardial mitochondrial permeability transition pore, which is limited by its myocardial distribution.}

\section{Mathieu Panel, Abdelhakim Ahmed-Belkacem, Isaac Ruiz, Jean-François Guichou, Jean-Michel Pawlotsky, Bijan Ghaleh, and Didier Morin}

MP: U955 - IMRB, Inserm, UPEC, Ecole Nationale Vétérinaire d'Alfort, Créteil, France AAB : Université Paris-Est, UMR S955, UPEC, Créteil, France ; INSERM U955, Team «Viruses, Hepatology, Cancer », Hôpital Henri Mondor, Créteil, France.

IR : Université Paris-Est, UMR S955, UPEC, Créteil, France ; INSERM U955, Team « Viruses, Hepatology, Cancer », Hôpital Henri Mondor, Créteil, France.

JFG: Centre de Biochimie Structurale (CBS), INSERM U1054, CNRS UMR5048, Université de Montpellier, Montpellier, France.

JMP: Université Paris-Est, UMR S955, UPEC, Créteil, France ; INSERM U955, Team « Viruses, Hepatology, Cancer », Hôpital Henri Mondor, Créteil, France; Department of Virology, Hôpital Henri Mondor, Créteil, France.

BG: U955 - IMRB, Inserm, UPEC, Ecole Nationale Vétérinaire d'Alfort, Créteil, France. DM: U955 - IMRB, Inserm, UPEC, Ecole Nationale Vétérinaire d'Alfort, Créteil, France. 
Running Title page

a) Running Title: a novel inhibitor of myocardial mPTP

b) Corresponding Author:

Didier MORIN, PhD

INSERM U955, Team Ghaleh, Faculté de Médecine,

8 rue du général Sarrail, 94000, Créteil, France.

E-mail : didier.morin@inserm.fr.

c) Number of text pages: 30

Number of figures: 7

Number of references: 36

Number of words in the Abstract: 249

Number of words in the Introduction: 574

Number of words in the Discussion: 913

d) List of non -standard abbreviations: PTP, mitochondrial permeability transition pore; CypD, cyclophilin D; CsA, cyclosporine A; PPIase, peptidylprolyl cis-trans isomerase; CRC, calcium retention capacity.

e) Recommended section: Cardiovascular 


\section{Abstract}

Mitochondrial permeability transition pore (mPTP) opening is a key event in cell death during myocardial ischemia-reperfusion. Inhibition of its modulator cyclophilin D (CypD) by cyclosporine A (CsA) reduces ischemia-reperfusion injury. The use of cyclosporine A in this indication is debated, however, targeting mPTP remains a major goal to achieve. We investigated the protective effects of a new original small-molecule cyclophilin inhibitor, C31, specifically designed to target CypD. CypD peptidylprolyl cis-trans isomerase PPIase activity was assessed by the standard chemotrypsin coupled assay. The effects of C31 on mPTP opening was investigated in isolated mouse cardiac mitochondria by measuring mitochondrial swelling and calcium retention capacity (CRC), in rat $\mathrm{H} 9 \mathrm{C} 2$ cardiomyoblasts and in adult mouse cardiomyocytes by fluorescence microscopy, in isolated perfused mouse hearts and ex vivo after drug infusion in mice. C31 potently inhibited CypD PPIase activity and mitochondrial swelling. C31 was more effective at increasing mitochondrial CRC than CsA and was still able to increase CRC in Ppif ${ }^{/-}$(CypD-inactivated) cardiac mitochondria. C31 delayed both mPTP opening and cell death in cardiomyocytes subjected to hypoxiareoxygenation. However, high concentrations of both drugs were necessary to reduce mPTP opening in isolated perfused hearts and neither CsA nor C31 inhibited mPTP opening in heart after in vivo infusion, underlying the importance of myocardial drug distribution for cardioprotection. C31 is an original inhibitor of mPTP opening involving both CypDdependent and -independent mechanisms. It constitutes a promising new cytoprotective agent. Optimization of its pharmacokinetic properties is now required prior to its use against cardiac ischemia-reperfusion injury. 


\section{Significance Statement}

This study demonstrates that the new cyclophilin inhibitor C31 potently inhibits cardiac mPTP opening in vitro and ex vivo. The dual mechanism of action of $\mathrm{C} 31$ allows to prevent mPTP opening beyond CypD inhibition. Further development of the compound might bring promising drug candidates for cardioprotection. However, the lack of effect of both $\mathrm{C} 31$ and cyclosporine A following systemic administration demonstrates the difficulties of targeting myocardial mitochondria in vivo and should be taken into account in cardioprotective strategies. 


\section{Introduction}

Mitochondrial permeability transition pore (mPTP) opening is considered as a critical event in cell death during myocardial ischemia-reperfusion. Indeed, opening of the mPTP in the first minutes of reperfusion causes necrosis or apoptosis and participates in ischemia-reperfusion injury (Yellon and Haussenloy, 2007; Morin et al., 2009; Halestrap, 2010; Di Lisa et al., 2011; Haussenloy et al., 2016). Therefore, targeting mPTP opening represents an interesting pharmacological strategy to limit the damages induced by the reperfusion of an ischemic myocardium. Even though the molecular structure of mPTP remains debated, cyclophilin D (CypD) a mitochondrial peptidylprolyl cis-trans isomerase (PPiase), is widely described as an essential modulator of pore opening. CypD is located within the mitochondrial matrix and catalyzes or stabilizes the formation of the pore (Gutiérrez-Aguilar and Baines, 2015). Inhibition or genetic ablation of CypD strongly decreases the susceptibility to mPTP opening by lowering its sensitivity to $\mathrm{Ca}^{2+}$ overload. Therefore, $\mathrm{CypD}$ became an attractive target to develop cardioprotective strategies. Animal studies demonstrated that CypD inhibition with cyclosporine A (CsA), hence de-sensitization of mPTP opening, decreased infarct size (Trankle et al., 2016). Clinical translation of CypD inhibition by CsA administered at reperfusion in patients during acute myocardial infarction demonstrated decreased biomarker release and less adverse remodeling (Piot et al., 2008; Mewton et al., 2010). However, the phase III clinical trial CIRCUS did not confirm the beneficial effects of CsA observed previously (Cung et al., 2015). The failure to achieve the CIRCUS predefined efficacy endpoint has been extensively discussed and differences between the two trials, unrelated to CsA per se, may account for the discrepancy of the results (Chen-Scarabelli and Scarabelli, 2016; Heusch, 2015; Monassier et al., 2016). mPTP opening can also occur in a CypDindependent manner and this might explain at least in part the difference between clinical studies. Indeed, CypD is only a modulator of mPTP opening and its inhibition de-sensitizes 
mPTP opening rather than blocking it (Bernardi et al., 2006; Halestrap and Richardson, 2015).

Hence, mPTP opening remains achievable in case of very strong stimuli. These findings stimulated several groups to develop chemical strategies to identify novel selective and nonpeptidic compounds able to inhibit mPTP opening. Our group used fragment-based drug discovery combined with a linking strategy and structure-based compound optimization to generate a new family of non-peptidic, small-molecule cyclophilin inhibitors, unrelated to CsA or Sanglifehrin A, with strong PPIase inhibitory activity (Ahmed-Belkacem et al., 2016). These compounds target cyclophilins by interacting with the PPiase domain and anchoring in the adjacent gatekeeper pocket (Ahmed-Belkacem et al., 2016). They bind into the active site of cyclophilins competitively with cyclosporine A (Nevers et al., 2018). We previously described that the most active compound, C31 (1-(4-aminobenzyl)-3-(2-(2-(2(methylthio)phenyl)pyrrolidin-1-yl)-2-oxo-1-phenylethyl)urea), is an effective mPTP inhibitor, which exerts protective effects in the context of hepatic ischemia-reperfusion injury through an original mechanism involving CypD at low concentrations and another target at higher concentrations (Panel et al., 2019).

Here, we compared the effect of $\mathrm{C} 31$ on mPTP opening in mouse liver and cardiac mitochondria. We demonstrated that $\mathrm{C} 31$ inhibits mPTP opening in isolated cardiac mitochondria with a dual mechanism identical to that observed in the liver. This effect was correlated with cytoprotective effects in cardiomyocytes subjected to hypoxia-reoxygenation. Perfusion of CsA and C31 in Langendorff-perfused heart model showed that high concentrations of both compounds are required to inhibit mPTP opening. Strikingly, neither C31 nor CsA reached cardiac mitochondria after in vivo administration, emphasizing the need to improve intramitochondrial delivery of compound $\mathrm{C} 31$ for further therapeutic development. 


\section{Materials and Methods}

\section{Ethics statement}

All animal procedures used in this study were in accordance with the Directives of the European Parliament (2010/63/EU-848 EEC) and were approved by the Animal Ethics Committee Afssa/ENVA/Université Paris-Est Créteil (approval number 09/12/14-02) and by the French Ministry of Higher Education and Research (APAFIS\#13504, December 18, 2017).

\section{Drugs and cells}

Unless specified, all reagents were purchased from Sigma Aldrich (Saint-Quentin Fallavier, France). Calcein AM (C3100MP) and calcium Green 5N (C3737) were obtained from Invitrogen (Cergy-Pontoise, France). C31 was synthesized as previously described (AhmedBelkacem et al., 2016).

Rat H9C2 cells were obtained from the American Tissue Culture Collection (LGC Standards S.a.r.l., Molsheim, France) and were cultured in complete medium consisting of Dulbecco's modified Eagle's medium (DMEM) supplemented with $10 \%$ fetal bovine serum, $4 \mathrm{mM} \mathrm{L-}$ glutamine, 100 units $/ \mathrm{ml}$ penicillin, and $0.1 \mathrm{mg} / \mathrm{ml}$ streptomycin. Cells were used between passage 20 and 25 and were seeded in complete medium in $35 \mathrm{~mm}$ Petri dishes $24 \mathrm{~h}$ before microscopy experiments.

\section{Animals}

Male C57BL/6J mice (8 to 10 week-old) and male Wistar rats (250-300g) were purchased from Janvier (Le Genest-St-Isle, France). CypD knock-out mice (Ppif ${ }^{-{ }_{-}}$mice) were obtained from Jackson Laboratories (Bar Harbor, Maine, USA). Animals were housed in an air- 
conditioned room with a $12 \mathrm{~h}$ light-dark cycle and received standard rodent chow and drinking water ad libitum.

\section{Isolation of mitochondria and cytosols}

For swelling experiments and evaluation of mitochondrial $\mathrm{Ca}^{2+}$ retention capacity left ventricle tissues from C57BL6/J wild type, Ppif ${ }^{/-}$mice or male Wistar rats were removed after cervical dislocation (mice) and sodium pentobarbital (80 mg/kg) anesthesia (rats). They were immediately immersed in ice cold $0.9 \% \mathrm{NaCl}$, scissor minced and homogenized using a Polytron homogenizer in a cold buffer $\left(4{ }^{\circ} \mathrm{C}, \mathrm{pH}\right.$ 7.4) containing: mannitol $(220 \mathrm{mM})$, sucrose (70 $\mathrm{mM})$, HEPES $(10 \mathrm{mM})$ and EGTA $(2 \mathrm{mM})$. The samples were further homogenized for 10 consecutive times using a Potter homogenizer at $1500 \mathrm{rev} / \mathrm{min}$. The homogenates were then centrifuged at $1000 \mathrm{~g}$ for $5 \mathrm{~min}$ at $4^{\circ} \mathrm{C}$ to remove tissue debris and nuclei. The supernatants were centrifuged for $10 \mathrm{~min}$ at $10,000 \mathrm{~g}$. The final mitochondrial pellets were resuspended in the homogenization buffer with only $0.01 \mathrm{mM}$ of EGTA and protein concentration was determined using the Advanced protein assay reagent (Sigma catalog number \#57697).

For evaluation of PPIase activity, C57BL/6J mice hearts and livers were used to prepare mitochondrial and cytosolic extracts. Mitochondria were purified on a Percoll@ gradient (Townsend et al., 2007) as follows. Briefly, the left ventricle tissues were added to $5 \mathrm{ml}$ of homogenization buffer (mannitol $(220 \mathrm{mM})$, sucrose $(70 \mathrm{mM})$, HEPES $(10 \mathrm{mM})$ and EGTA $(2 \mathrm{mM}), \mathrm{pH} 7.4$ at $4^{\circ} \mathrm{C}$ ) supplemented with $0.25 \%$ bovine serum albumin. The tissues were sliced and homogenized with a Potter-Elvehjem glass homogenizer by a motor-driven Teflon pestle at $1500 \mathrm{rpm}$ in a final volume of $5 \mathrm{ml}$. Homogenates were centrifuged at 1,000 $\mathrm{g}$ for 5 $\min$ at $4^{\circ} \mathrm{C}$. Then supernatants were centrifuged at $10,000 \mathrm{~g}$ for $10 \mathrm{~min}$ at $4^{\circ} \mathrm{C}$ to pellet 
mitochondrial fractions. The resulting supernatants were centrifuged at 100,000 g for $60 \mathrm{~min}$ at $4{ }^{\circ} \mathrm{C}$ to obtain cytosolic fractions.

Mitochondrial pellets were added to $500 \mu$ l of homogenization buffer supplemented with $20 \%$ Percoll ${ }^{\circledR}$. Homogenates were centrifuged at $15,000 \mathrm{~g}$ for $10 \mathrm{~min}$ at $4^{\circ} \mathrm{C}$ in a final volume of $10 \mathrm{ml}$. Supernatants were carefully removed and pellet added to $10 \mathrm{ml}$ of homogenization buffer (without Percoll®) before centrifugation at $12,000 \mathrm{~g}$ for $5 \mathrm{~min}$ at $4^{\circ} \mathrm{C}$. The final mitochondrial pellets were resuspended in the homogenization buffer. Sample protein concentrations were determined using the Advanced protein assay reagent (Sigma catalog number \#57697).

\section{Evaluation of peptidyl-prolyl cis-trans isomerase (PPIase) activity}

PPIase activity was evaluated at $25^{\circ} \mathrm{C}$ using the standard chymotrypsin coupled assay. Mitochondrial or cytosolic fractions $(0.3 \mathrm{mg}$ protein $/ \mathrm{ml})$ were incubated in the assay buffer (220 mM mannitol, $70 \mathrm{mM}$ sucrose, $10 \mathrm{mM}$ HEPES, $4 \mathrm{mM}$ EGTA, $\mathrm{pH} 7.4$ at $4^{\circ} \mathrm{C}$ ) in the presence of $5 \mu \mathrm{L}$ of $50 \mathrm{mg} / \mathrm{ml}$ chymotrypsin (in $1 \mathrm{mM} \mathrm{HCl}$ ). After a $20 \mathrm{~s}$ stabilization period, reaction was initiated by adding $20 \mu \mathrm{L}$ of $3.2 \mathrm{mM}$ peptide substrate (N-Succinyl-Ala-Ala-ProPhe-p-nitroanilide). The absorbance of p-nitroanilide was followed at $390 \mathrm{~nm}$ for $1 \mathrm{~min}$. For the inhibition assays, $1 \mu \mathrm{M}$ CsA (in dimethylsulfoxide, DMSO) was added to the preparation in the assay buffer. PPIase activity was determined from the slopes of the curves.

\section{Mitochondrial swelling assays}

Mitochondrial swelling was assessed in energized rat cardiac mitochondria by measuring the change in absorbance at $540 \mathrm{~nm}\left(\mathrm{~A}_{540}\right)$ using a Jasco V-530 spectrophotometer (Jasco, Bouguenais, France) equipped with magnetic stirring and thermostatic control. Experiments were carried out at $30^{\circ} \mathrm{C}$ in a respiration buffer including $100 \mathrm{mM} \mathrm{KCl}, 50 \mathrm{mM}$ sucrose, 10 
mM HEPES, $5 \mathrm{mM} \mathrm{KH} \mathrm{PO}_{4}\left(\mathrm{pH} 7.4\right.$ at $\left.30^{\circ} \mathrm{C}\right)$. Mitochondria $(0.5 \mathrm{mg} / \mathrm{mL})$ were incubated in the presence of pyruvate/malate ( $5 \mathrm{mM}$ each). After $30 \mathrm{~s}$, swelling was induced by addition of $250 \mu \mathrm{M} \mathrm{CaCl}_{2}$. The determination of the initial rate of swelling allowed calculating the $\mathrm{IC}_{50}$ values as previously described (Elimadi et al., 1997).

\section{Evaluation of the $\mathrm{Ca}^{2+}$ retention capacity (CRC) of isolated mitochondria}

Rat or mouse cardiac mitochondria were loaded with increasing concentrations of $\mathrm{Ca}^{2+}$ until the load reached a threshold at which mitochondria underwent a fast process of $\mathrm{Ca}^{2+}$ release, which was due to mPTP opening, as previously described (Obame et al., 2008). Mitochondria $(0.8 \mathrm{mg} / \mathrm{ml})$, energized with $5 \mathrm{mM}$ glutamate/malate, were incubated in the respiration buffer supplemented with $1 \mu \mathrm{M}$ Calcium Green-5N fluorescent probe. The concentration of $\mathrm{Ca}^{2+}$ in the extramitochondrial medium was monitored by means of a Jasco FP-6300 spectrofluorimeter (Jasco, Bouguenais, France) at excitation and emission wavelengths of 506 and $532 \mathrm{~nm}$, respectively. The $\mathrm{Ca}^{2+}$ signal was calibrated by addition to the medium of known $\mathrm{Ca}^{2+}$ amounts.

\section{Isolation of primary adult mouse cardiomyocytes}

Ventricular cardiomyocytes were isolated from mice by an enzymatic technique. Mice were anesthetized with sodium pentobarbital $(100 \mathrm{mg} / \mathrm{kg})$ and hearts were removed. The heart was retrogradely perfused for $15 \mathrm{~min}$ at $37^{\circ} \mathrm{C}$ with a stock perfusion buffer bubbled with $95 \% \mathrm{O}_{2} / 5 \% \mathrm{CO}_{2}$ containing $133 \mathrm{mM} \mathrm{NaCl}, 4.7 \mathrm{mM} \mathrm{KCl}, 0.6 \mathrm{mM} \mathrm{KH}_{2} \mathrm{PO}_{4}, 0.6 \mathrm{mM} \mathrm{Na}_{2} \mathrm{HPO}_{4}$, $1.2 \mathrm{mM} \mathrm{MgSO}_{4}, 12 \mathrm{mM} \mathrm{NaHCO} 3,10 \mathrm{mM} \mathrm{KHCO} 3,10 \mathrm{mM}$ HEPES, $30 \mathrm{mM}$ taurine, 0.032 $\mathrm{mM}$ phenol red, $5.5 \mathrm{mM}$ glucose, $10 \mathrm{mM}$ 2,3-butanedionemonoxime $\mathrm{pH} 7.4$ to wash out blood. After $2 \mathrm{~min}$ of perfusion, liberase TM (10 mg/100 ml, Roche Applied Science, Mannheim, Germany), trypsin EDTA $(14 \mathrm{mg} / 100 \mathrm{ml})$ and $12.5 \mu \mathrm{M} \mathrm{Ca}^{2+}$ were added to the 
buffer and the heart was perfused for approximately 8-9 min. The heart was placed into a beaker in the same buffer supplemented with $10 \%$ bovine serum albumin $\mathrm{pH} 7.4$ at $37^{\circ} \mathrm{C}$ to stop the digestion. Ventricles were then cut into small fragments and cells isolated by stirring the tissue and successive aspirations of the fragments through a $10 \mathrm{ml}$ pipette. Cell suspension was filtered (250 - $\mu \mathrm{m}$ nylon mesh) and decanted for $10 \mathrm{~min}$. The pellet (containing the cells) was resuspended in $10 \mathrm{ml}$ of the perfusion buffer including $5 \%$ bovine serum albumin and $12.5 \mu \mathrm{M}$ of $\mathrm{Ca}^{2+}$. The cellular suspension was decanted again for $10 \mathrm{~min}$. The supernatant was eliminated and the same procedure (resuspension and settling) was repeated with increasing concentrations of $\mathrm{Ca}^{2+}(62,112,212,500 \mu \mathrm{M})$ up to $1 \mathrm{mM}$. Finally, cardiomyocytes were suspended in a M199 culture medium, seeded on $35 \mathrm{~mm}$ Petri dishes pre-coated with 10 $\mu \mathrm{g} / \mathrm{ml}$ sterilised laminin and incubated for $90 \mathrm{~min}$ at $37^{\circ} \mathrm{C}$ before being used.

\section{Measurement of mPTP opening in rat cardiomyoblastic $\mathrm{H9C2}$ cells in normoxic conditions}

Direct assessment of mPTP opening in rat cardiomyoblastic H9C2 cell line was performed using the established loading procedure of the cells with calcein acetoxymethyl ester (calcein$\mathrm{AM}$ ) and $\mathrm{CoCl}_{2}$ resulting in mitochondrial localization of calcein fluorescence (Petronilli et al., 1999). Cells were loaded with $2 \mathrm{mM} \mathrm{CoCl}_{2}$ at $30^{\circ} \mathrm{C}$ in $1 \mathrm{ml}$ of Tyrode's solution (in mM: $\mathrm{NaCl} 130 ; \mathrm{KCl} 5$; HEPES $10 ; \mathrm{MgCl}_{2} 1 ; \mathrm{CaCl}_{2} 1.8, \mathrm{pH}=7.4$ at $37^{\circ} \mathrm{C}$ ) for $30 \mathrm{~min}$. After $10 \mathrm{~min}$ cells were supplemented with $1 \mu \mathrm{M}$ calcein-AM. This labelling protocol was slightly different from that used in our previous studies performed with adult cardiomyocytes (Petronilli et al., 2001; Obame et al., 2008), but it was necessary to obtain the best labelling of the cells. Cells were then washed free of calcein and $\mathrm{CoCl}_{2}$ with the Tyrode's solution and placed in a thermostated chamber (Warner Instruments Inc, Connecticut, USA) which was mounted on the stage of an IX81 Olympus microscope (Olympus, Rungis, France). After 5 min of 
incubation in the Tyrode's medium, $50 \mathrm{nM}$ of the $\mathrm{Ca}^{2+}$ ionophore $\mathrm{A} 23187$ was added to the cells to induce mPTP opening as previously described (Schaller et al., 2010). When specified, C31 or CsA was added to the cells at the beginning of the incubation period.

\section{Measurement of mPTP opening in primary adult cardiomyocytes subjected to hypoxia- reoxygenation}

Mouse cardiomyocytes were placed into a thermostated $\left(37^{\circ} \mathrm{C}\right)$ chamber (Warner Instruments Inc, Connecticut, USA) which was mounted on the stage of an IX81 Olympus microscope (Olympus, Rungis, France) and were perfused with the Tyrode's solution at a rate of 0.5 $\mathrm{ml} / \mathrm{min}$. The chamber was connected to a gas bottle diffusing a constant stream of $\mathrm{O}_{2}(21 \%)$, $\mathrm{N}_{2}(74 \%)$ and $\mathrm{CO}_{2}(5 \%)$ maintaining an $\mathrm{O}_{2}$ concentration of $21 \%$. Oxygen in the perfusate was measured in the chamber using a fibre optic sensor system (Ocean Optics Inc., Florida, USA). Cardiomyocytes were paced to beat by field stimulation $(5 \mathrm{~ms}, 0.5 \mathrm{~Hz})$.

To simulate ischaemia, the perfusion was stopped and cardiomyocytes exposed for 45 min to a hypoxic medium maintaining an $\mathrm{O}_{2}$ concentration of 1-2\%. This medium was the Tyrode's solution (bubbled with $100 \% \mathrm{~N}_{2}$ ) supplemented with $20 \mathrm{mM}$ 2-deoxyglucose and subjected to a constant stream of $\mathrm{N}_{2}(100 \%)$. At the end of the ischemic period, reoxygenation was induced by rapidly restoring the Tyrode's flow and $21 \% \mathrm{O}_{2}$ in the chamber.

In these cells, mPTP opening was also assessed by means of the calcein loading procedure as previously described (Petronilli et al., 2001; Obame et al., 2008). Briefly, before introduction in the thermostated chamber, cells were loaded with $1 \mu \mathrm{M}$ calcein-AM at $37^{\circ} \mathrm{C}$ for $30 \mathrm{~min}$ supplemented with $1 \mathrm{mM} \mathrm{CoCl}_{2}$ after $20 \mathrm{~min}$ of incubation. To determine cell death, cardiomyocytes were co-loaded with $1.5 \mu \mathrm{M}$ propidium iodide which permeates only the damaged cells. 


\section{Data acquisition and analysis of fluorescence microscopy experiments.}

Cells were imaged with an Olympus IX-81 motorized inverted microscope equipped with a mercury lamp as a source of light for epifluorescence illumination and with a 12-bit cooled Hamamatsu ORCA-ER camera (Hamamatsu, Hamamatsu city, Japan). For detection of calcein fluorescence a 460-490 $\mathrm{nm}$ excitation and a $510 \mathrm{~nm}$ emission filters were used. In normoxic experiments, images were acquired every $5 \mathrm{~min}$ for $30 \mathrm{~min}$ after an illumination time of $25 \mathrm{~ms}$ per image using a digital epifluorescence imaging software (Cell M, Olympus, Rungis, France). In hypoxia-reoxygenation experiments, images were acquired every 5 min during hypoxia, every min throughout the first $10 \mathrm{~min}$ of reoxygenation and then every $5 \mathrm{~min}$ for the remaining duration of the experiment after an illumination time of $25 \mathrm{~ms}$ (calcein) and $70 \mathrm{~ms}$ (propidium iodide).

Fluorescence was integrated over a region of interest $\left(\approx 80 \mu \mathrm{m}^{2}\right)$ for each cell and a fluorescence background corresponding to an area without cells was subtracted. Then, the global response was analysed by averaging the fluorescence changes obtained from all the cells (25-30) contained in a single field.

For calcein experiments, intensity values were normalized according to the initial fluorescence values after subtracting background. Moreover, we calculated the average time to $\mathrm{mPTP}$ opening $\left(\mathrm{t}_{\mathrm{mPTP}}\right)$ in each experiment by measuring the reoxygenation time necessary to reach $50 \%$ decrease in calcein fluorescence intensity for each cell with opened $\mathrm{mPTP}$ in the field. Propidium iodide fluorescence intensity minus background was normalized to $100 \%$ cell death.

\section{Ex vivo assessment of mPTP opening in mice and in isolated perfused hearts.}

The ability of $\mathrm{C} 31$ and $\mathrm{CsA}$ to interact with $\mathrm{CypD}$ in vivo was evaluated by measuring their ability to inhibit mPTP after mitochondrial isolation according to the following protocol. 
Mice were anesthetized with intraperitoneal injection of sodium pentobarbital $(80 \mathrm{mg} / \mathrm{kg})$. The depth of anesthesia was monitored using the tail pinching response and the pedal reflex. Increasing doses of $\mathrm{C} 31(10,20,50$ and $150 \mathrm{mg} / \mathrm{kg}), \mathrm{CsA}(20 \mathrm{mg} / \mathrm{kg})$ or vehicle were administered at random as a 3 min infusion through the jugular vein. Two min after the end of the infusion, hearts and livers were excised and mitochondria were isolated to measure their capacity to retain $\mathrm{Ca}^{2+}$.

The ability of C31 and CsA to interact with CypD was also evaluated in isolated perfused mouse hearts. Wild type mouse hearts were retrogradely perfused through the aorta with a perfusion medium $\left(133 \mathrm{mM} \mathrm{NaCl}, 4.7 \mathrm{mM} \mathrm{KCl}, 0.6 \mathrm{mM} \mathrm{KH}_{2} \mathrm{PO}_{4}, 0.6 \mathrm{mM} \mathrm{Na} 2 \mathrm{HPO}_{4}, 1.2\right.$ $\mathrm{mM} \mathrm{MgSO} 4,12 \mathrm{mM} \mathrm{NaHCO} 3,10 \mathrm{mM} \mathrm{KHCO} 3,10 \mathrm{mM}$ HEPES, $30 \mathrm{mM}$ taurine, $5.5 \mathrm{mM}$ glucose, $10 \mathrm{mM}$ 2,3-butanedionemonoxime, $\mathrm{pH} 7.4$ at $\left.37^{\circ} \mathrm{C}\right)$ containing DMSO (0.1\%), CsA $(2-10 \mu \mathrm{M})$ or $\mathrm{C} 31(100 \mu \mathrm{M})$. Perfusion pressure was set at $120 \mathrm{mmHg}$ in non-recirculating mode and, after a 20 min perfusion, cardiac mitochondria were isolated and $\mathrm{Ca}^{2+}$ retention capacity was evaluated. For each preparation, maximal CypD-dependent $\mathrm{Ca}^{2+}$ retention capacity achievable was further assessed in vitro by adding $1 \mu \mathrm{M}$ CsA to the mitochondrial suspension.

\section{Data and statistical analysis}

The data and statistical analysis comply with the recommendations on experimental design and analysis in pharmacology. Statistical analysis was performed using GraphPad prism v.6. Results are expressed as mean \pm SEM. Difference among groups was assessed by one-way ANOVA analysis and was followed by Tukey's multiple comparison test if ANOVA produced a significant value of $\mathrm{F}(\mathrm{p}<0.05)$. For isolated perfused heart experiments, two different tests were used: a non-parametric Kruskall-Wallis multiple comparison test followed by Dunnett's post hoc test to compare CRC achieved by drug administration; a 2-way 
ANOVA with paired values (CRC and CRC + CsA), followed by Fisher's LSD test to analyse the effect of CsA addition in vitro. Statistical significance was defined as a value of $\mathrm{p}<0.05$. 


\section{Results}

\section{C31 inhibits mPTP opening in isolated cardiac mitochondria}

We tested whether C31 was able to inhibit mPTP opening in isolated cardiac mitochondria. Isolated rat cardiac mitochondria were energized with pyruvate plus malate and exposed to $250 \mu \mathrm{M} \mathrm{Ca}^{2+}$ in the presence of phosphate to trigger swelling. Swelling was fully inhibited by $2 \mu \mathrm{M}$ CsA, a well-known desensitizer of mPTP opening, confirming that the observed change in absorbance was due to $\mathrm{mPTP}$ opening. In these conditions, C31 inhibited mitochondrial swelling in a concentration-dependent manner (Figure 1). The $\mathrm{IC}_{50}$ obtained for both CsA and $\mathrm{C} 31\left(\mathrm{IC}_{50}=0.044 \pm 0.001\right.$ and $1.29 \pm 0.35 \mu \mathrm{M}$, respectively $)$ were comparable between cardiac and liver mitochondria, recently reported for the latter (Panel et al., 2019). Thus, C31 inhibits mPTP opening in cardiac mitochondria, to a similar extent as what we recently observed in liver mitochondria.

Next, we evaluated the effect of $\mathrm{C} 31$ on cardiac mitochondrial CRC, i.e., a sensitive assay to analyze mPTP inhibition or sensitization (Fontaine et al., 1998). This technique is complementary to swelling experiments as it allows to determine the maximal $\mathrm{Ca}^{2+}$ loading achievable in the presence of a drug before MPTP opening. Rat cardiac mitochondria required $143 \pm 14 \mu \mathrm{M} \mathrm{Ca}^{2+}$ before mPTP opening. Figure $2 \mathrm{a}$ and $2 \mathrm{~b}$ show that the maximal effect of CsA allowed mitochondria to retain twice $(287 \pm 29 \mu \mathrm{M}, \mathrm{p}<0.05)$ the amount of $\mathrm{Ca}^{2+}$ as compared to control (DMSO) treated mitochondria. Interestingly, $\mathrm{C} 31$ increased $\mathrm{Ca}^{2+}$ retention in a concentration-dependent manner and was significantly more effective than CsA, with a significantly greater CRC $(405 \pm 48 \mu \mathrm{M}$ at $100 \mu \mathrm{M})$.

\section{C31 exerts additional mPTP inhibiting properties independently from CypD}

To decipher the mechanism by which $\mathrm{C} 31$ exerts a stronger mPTP inhibition than CsA, CRC was assessed in cardiac mitochondria isolated from $\mathrm{Ppif}^{\prime-}$ mice. CRC under CsA was similar 
to control conditions in Ppif ${ }^{/-}$mitochondria $(164 \pm 17 \mu \mathrm{M})$ and was comparable to that obtained in wild-type mitochondria treated with $1 \mu \mathrm{M}$ CsA $(148 \pm 17 \mu \mathrm{M})$, indicating that CsA totally inhibited CypD in these mitochondria (Figure 2c and 2d). $100 \mu \mathrm{M} \mathrm{C} 31$ exhibited significantly greater CRC. These results show that a CypD-independent mechanism participates in mPTP inhibition by $\mathrm{C} 31$, in addition to the CypD-dependent mechanism.

\section{C31 inhibits mPTP opening in cells and delays hypoxia-reoxygenation-induced cell death}

We then investigated the protective effect of C31 in whole cells. In the first step, rat cardiomyoblast $\mathrm{H} 9 \mathrm{C} 2$ cells were loaded with $1 \mu \mathrm{M}$ calcein in the presence of $1 \mathrm{mM} \mathrm{CoCl} 2$ for $30 \mathrm{~min}$ at $37^{\circ} \mathrm{C}$. Cells were treated with DMSO $(0.1 \%)$, increasing concentrations of CsA $(0.2,2$ and $5 \mu \mathrm{M})$ or $\mathrm{C} 31(20,50$ and $100 \mu \mathrm{M})$. Then, mPTP opening was induced by exposing cells to the $\mathrm{Ca}^{2+}$ ionophore $\mathrm{A} 23187(50 \mathrm{nM})$, which resulted in a drop in calcein fluorescence (Figure $3 \mathrm{~b}$ and 3c). Treatment with $2 \mu \mathrm{M}$ CsA partially reduced the decrease in calcein fluorescence. This was the most effective concentration and we did not observed any effect at 0.2 and $5 \mu \mathrm{M}$. This confirmed the studies indicating that CsA in only protective within a narrow concentration range (Halestrap et al., 2004). C31 inhibited calcein loss in a concentration-dependent manner and totally abrogated mPTP opening at $100 \mu \mathrm{M}$ (Figure $3 \mathrm{~b}$ and $3 \mathrm{c})$.

Cytoprotective effect of C31 was then assessed in freshly isolated adult murine cardiomyocytes subjected to 45 min hypoxia followed by 180 min reoxygenation to mimic ischemia-reperfusion. Freshly isolated adult cardiomyocytes were co-loaded with calcein$\mathrm{AM}, \mathrm{CoCl}_{2}$ and propidium iodide. They were electrically paced and imaged during the whole procedure to monitor mPTP opening and cell death. Hypoxic medium was supplemented with CsA $(2 \mu \mathrm{M})$ or $\mathrm{C} 31(100 \mu \mathrm{M}, 0.1 \%$ DMSO) 15 min before reoxygenation and the compounds 
were further present in the perfusion medium during the first $10 \mathrm{~min}$ of reoxygenation (Figure 4a). As shown in Figure 4b, reoxygenation induced mPTP opening with a mean time for $50 \%$ mPTP opening $\left(\mathrm{t}_{\mathrm{mPTP} 50}\right)$ of $62 \pm 13 \mathrm{~min}$ in control conditions. Surprisingly, in these cardiomyocytes, CsA was not able to delay mPTP opening $\left(\mathrm{t}_{\mathrm{mPTP} 50}=55 \pm 6 \mathrm{~min}\right)$ and cell death (Figure $4 \mathrm{~b}$ and $4 \mathrm{c}$ ) whereas CypD gene deletion delayed calcein loss and cell death in the same model (Panel et al., 2017). In accordance with the results obtained in H9C2 cells (Figure 3), increasing CsA concentration to 5 or $10 \mu \mathrm{M}$ did not afford more protection (data not shown). In contrast, $\mathrm{C} 31$ delayed $\mathrm{mPTP}$ opening $\left(\mathrm{t}_{\mathrm{mPTP} 50}=120 \pm 8 \mathrm{~min}\right)$ and this was associated with a reduction in cell death (Figure $4 \mathrm{~b}, 4 \mathrm{c}$ and $4 \mathrm{~d}$ ). These results demonstrate that C31 permeates cell membranes and protects cardiomyocytes from mPTP opening.

\section{High CypD inhibitor concentrations are required to inhibit mPTP opening in isolated perfused heart}

The next part of this work was designed to study the ability of CypD inhibitors to reach CypD ex vivo using a mouse model of isolated perfused heart. In these experiments, wild type mouse hearts were retrogradely perfused through the aorta with a perfusion medium containing DMSO $(0.1 \%)$, CsA $(2-10 \mu \mathrm{M})$ or C31 $(100 \mu \mathrm{M})$. After a 20 min perfusion, cardiac mitochondria were isolated and CRC was evaluated in the presence or not of $1 \mu \mathrm{M}$ CsA added directly to the mitochondria in the medium, a CsA concentration inhibiting totally CypD (see previously). As shown in Figure 5, control mitochondria retained 61.3 $\pm 5.5 \mu \mathrm{M}$ $\mathrm{Ca}^{2+}$ before mPTP opening and this retention doubled by adding $1 \mu \mathrm{M}$ CsA $(115.0 \pm 2.9 \mu \mathrm{M})$ in the incubation medium. Interestingly, heart perfusion of $2 \mu \mathrm{M}$ CsA only increased the $\mathrm{Ca}^{2+}$ retention capacity to $96.2 \pm 6.2 \mu \mathrm{M}(+56.9 \%$ versus control value) which reflects a weak inhibition of CypD activity. CsA concentration had to be increased to $10 \mu \mathrm{M}$ to obtain a full inhibition of CypD-dependent mPTP opening. In these conditions, perfusion with $100 \mu \mathrm{M}$ 
C31 allowed to retain $100.8 \pm 4.5 \mu \mathrm{M} \mathrm{Ca}^{2+}$, inducing a partial inhibition of CypD. These data demonstrate that CypD inhibitors are able to reach cardiac mitochondria when they are directly perfused to the heart. Nevertheless, a total inhibition of CypD required high concentrations of CsA and it was impossible to obtain this effect with C31, even at the highest concentration obtainable in solution (100 $\mu \mathrm{M}$, solubility limitation).

\section{C31 reaches liver but not cardiac mitochondria in a mouse model in vivo}

Based on our previous results demonstrating that $\mathrm{C} 31$ inhibits $\mathrm{mPTP}$ opening in mouse liver after in vivo administration (Panel et al., 2019), we questioned whether C31 was also able to inhibit mPTP in cardiac mitochondria when administrated to living mice. C57BL/6J mice were infused with either vehicle, $20 \mathrm{mg} \cdot \mathrm{kg}^{-1} \mathrm{CsA}$ or increasing concentrations of C31, ranging from $10 \mathrm{mg} \cdot \mathrm{kg}^{-1}$ to $150 \mathrm{mg} \cdot \mathrm{kg}^{-1}$, i.e. the dose that was previously described as the most efficient in liver studies. Hearts and livers were excised 2 min after the end of infusion and mitochondria were isolated. In C31-treated mice, CRC in cardiac mitochondria was not changed as compared to mice receiving vehicle, although liver mitochondria demonstrated increased CRC with both C31 and CsA (Figure 6). The same lack of effect was observed when mice were treated with $20 \mathrm{mg} \cdot \mathrm{kg}^{-1} \mathrm{CsA}$, as mitochondria exhibited CRC indistinguishable from vehicle. These results suggest that neither C31 nor CsA reached cardiac mitochondria in our experimental conditions.

Cytosolic cyclophilins are not responsible for the absence of in vivo effect of CsA and C31

A possible factor hampering CypD inhibitors to reach cardiac mitochondrial matrix might rely on the presence of extramitochondrial cyclophilins, such as cyclophilin A, which is abundant in the cytosol (Wang and Heitman, 2005). We hypothesized that CsA or C31 could interact with these cytosolic cyclophilins, preventing their translocation to mitochondria. Thus, we 
evaluated PPIase activity of mitochondrial and cytosolic extracts of mouse liver and heart. Figure 7a shows that, at the same protein concentration, the rate of peptide isomerization was lower in mitochondria than in cytosols. This tends to indicate that the ratio of PPIase proteins over total protein is lower in mitochondria. Besides this difference, PPIase activity was similar in each compartment in both tissues (Figure $7 \mathrm{~b}$ and $7 \mathrm{c}$ ), indicating that a difference in PPIase activity cannot explain the discrepancy observed in vivo between the two organs. 


\section{Discussion}

mPTP is thought to play a major role in myocardial ischemia-reperfusion injury. Indeed, the cellular conditions that prevail at reperfusion match those required to trigger mPTP opening. $\mathrm{Ca}^{2+}$ overload, oxidative stress, high phosphate concentrations and adenine nucleotide depletion encountered by cardiomyocytes are known to induce translocation of CypD to membrane mPTP components which will, in turn, favor opening of the pore. Inhibition of mPTP opening by targeting CypD results in decreased infarct size in numerous animal models and was translated to clinical studies. The phase III clinical trials CIRCUS (Cung et al., 2015) and CYCLE (Otatani et al., 2016) failed to confirm the beneficial effect of CsA previously observed (Piot et al., 2008). These results have been extensively commented elsewhere and several hypotheses have been proposed to explain CsA failure (Chen-Scarabelli and Scarabelli, 2016; Monassier et al., 2016). Nevertheless, CypD inhibition and, more broadly, mPTP blockade remain major goals to achieve and an interesting drug target.

The present study shows that C31, a small-molecule cyclophilin inhibitor derived from phenyl-pyrrolidine, inhibits mPTP opening in mouse cardiac mitochondria. Interestingly, high concentrations of $\mathrm{C} 31$ still increase $\mathrm{Ca}^{2+}$ retention capacity in mitochondria issued from Ppif ${ }^{/-}$ mice. This indicates that, in addition to its CypD-inhibiting properties, C31 inhibits mPTP opening through another mechanism which remains to be elucidated. This compound is therefore of particular interest because it escapes the limitations imposed by the regulatory role of CypD in mPTP function. Indeed, mPTP opening can still occur in the absence of CypD (Baines et al., 2005), but also when the stress conditions imposed to the cell are strong, which limits this pharmacological strategy. Such stress conditions might have been encountered in our experimental conditions by isolated cardiomyocytes in the hypoxiareoxygenation model. Indeed, C31 delayed mPTP opening and cell death, whereas CsA was 
totally ineffective on both phenomena. This suggests that $\mathrm{C} 31$ might be more effective in inducing cardioprotection than CsA.

The present study emphasizes a role for mitochondrial targeting and bioavailability of such inhibitors within the heart itself. Indeed, we observed that inhibition of mPTP required high CsA concentrations to fully inhibit CypD in a model of isolated perfused heart. This suggests that drug uptake by cardiomyocytes and mitochondrial delivery remain limited, even in the absence of other organs potentially extracting the compound from the blood. In the context of whole organism, only $5 \%$ of the cardiac output is distributed to the heart itself through coronary blood flow. In these conditions, only a low fraction of the administered compound reaches the myocardium and its mitochondrial compartment at the time of reperfusion, i.e., probably too low to permit protection of the cells. This is clearly demonstrated by our data showing that systemic administration of CsA and C31 inhibited mPTP opening in the liver but not in the heart. Therefore, systemic intravenous administration of mitochondrial protective agents might limit cardioprotection because of the massive uptake by the liver. This can explain, at least partly, the failure of the recent two large randomized clinical trials using CsA administered prior to percutaneous coronary intervention in patients (Cung et al., 2015; Davis et al., 2010). Thus, intracoronary administration of cardioprotective compounds at the time of percutaneous intervention might be more relevant to afford local protection within the area at risk.

Aside from myocardial drug distribution, other factors can influence mitochondrial targeting of the drugs. Proteins from the cyclophilin superfamily share the same catalytic site that is targeted by CsA and other cyclophilin inhibitors (Davis et al., 2010; Dunyak and Gestwicki, 2016). Therefore, exogenous inhibitors have to cross cell compartments filled with other cyclophilins than CypD before reaching mitochondrial matrix and thus might be entrapped outside mitochondria. This could limit mPTP inhibition and also participate in the lack of 
cardioprotection observed with CsA in recent clinical trials (Cung et al., 2015; Ottani et al., 2016). This is why we questioned whether other proteins than CypD exhibiting PPIase activity might hamper mitochondrial targeting. The present study showed that mitochondria exhibited lower PPiase activity than cytosol, reinforcing the idea of a possible entrapment by extramitochondrial cyclophilins. Thus, our data underline the urge to develop small inhibitors directly targeted to mitochondria. Such strategy has been mainly used for antioxidant agents (Silva et al., 2016) and can be obtained, for instance, by coupling compound with lipophilic cations such as triphenylphosphonium, which will accumulate into mitochondria in response to the membrane potential. A demonstration of the efficacy of this strategy was brought by Crompton's team who successfully coupled CsA to triphenylphosphonium cation. This resulted in $\mathrm{CsA}$ accumulation in mitochondria, a decrease in the concentration required to inhibit mPTP, as well as a lower cellular toxicity (Malouitre et al., 2009; Dube et al., 2012). Another strategy consists in the use of nanoparticles filled with protective compound. Previous work using nanoparticle-mediated mitochondrial targeting of CsA demonstrated that the compound accumulates predominantly in the area at risk, enhancing cardioprotection (Ikeda et al., 2016).

In conclusion, our results demonstrated that $\mathrm{C} 31$ is a strong inhibitor of $\mathrm{mPTP}$ opening in the myocardium. C31 combines both CypD-dependent and CypD-independent inhibitory effects, suggesting that it might be more effective than CsA to induce cardioprotection. Its low cardiac bioavailability limits its use in vivo, but optimization of this phenyl-pyrrolidine derivative aiming at increasing its metabolic stability and affinity might bring new interesting candidates to protect the heart against ischemia-reperfusion injury. This study also reveals that myocardial drug distribution may play a key role in the failure of mitochondrial agents to protect the myocardium, distribution parameters being often overlooked. 


\section{Authorship contributions}

Participated in research design: Panel, Ahmed-Belkacem, Ruiz, Pawlotsky, Ghaleh, Morin

Conducted experiments: Panel, Ahmed-Belkacem, Ruiz, Morin

Contributed new reagents: Guichou

Performed data analysis: Panel, Ahmed-Belkacem, Ruiz, Morin

Wrote or contributed to the writing of the manuscript: Panel, Ahmed-Belkacem, Ruiz, Guichou, Pawlotsky, Ghaleh, Morin 


\section{References}

Ahmed-Belkacem A, Colliandre L, Ahnou N, Nevers Q, Gelin M, Bessin Y, Brillet R, Cala O, Douguet D, Bourguet W, Krimm I, Pawlotsky JM, and Guichou JF (2016) Fragmentbased discovery of a new family of non-peptidic small-molecule cyclophilin inhibitors with potent antiviral activities. Nat Commun 7:12777. DOI: 10.1038/ncomms12777.

Baines CP, Kaiser RA, Purcell NH, Blair NS, Osinska H, Hambleton MA, Brunskill EW, Sayen MR, Gottlieb RA, Dorn GW, Robbins J, and Molkentin JD (2005) Loss of cyclophilin D reveals a critical role for mitochondrial permeability transition in cell death. Nature 434: 658-662. DOI: 10.1038/nature03434.

Bernardi P, Krauskopf A, Basso E, Petronilli V, Blachly-Dyson E, Di Lisa F, and Forte MA. (2006) The mitochondrial permeability transition from in vitro artifact to disease target. FEBS J. 273: 2077-2099. doi: 10.1111/j.1742-4658.2006.05213.x.

Chen-Scarabelli C and Scarabelli TM (2016) Cyclosporine A Prior to Primary PCI in STEMI Patients: The Coup de Grâce to Post-Conditioning? J Am Coll Cardiol 67: 375-378. DOI: 10.1016/j.jacc.2015.11.024.

Cung TT, Morel O, Cayla G, Rioufol G, Garcia-Dorado D, Angoulvant D, Bonnefoy-Cudraz E, Guérin P, Elbaz M, Delarche N, Coste P, Vanzetto G, Metge M, Aupetit JF, Jouve B, Motreff P, Tron C, Labeque JN, Steg PG, Cottin Y, Range G, Clerc J, Claeys MJ, Coussement P, Prunier F, Moulin F, Roth O, Belle L, Dubois P, Barragan P, Gilard M, Piot C, Colin P, De Poli F, Morice MC, Ider O, Dubois-Randé JL, Unterseeh T, Le Breton H, Béard T, Blanchard D, Grollier G, Malquarti V, Staat P, Sudre A, Elmer E, Hansson MJ, Bergerot C, Boussaha I, Jossan C, Derumeaux G, Mewton N, and Ovize M (2015) Cyclosporine before PCI in Patients with Acute Myocardial Infarction. New Engl J Med 373:1021-1031. DOI: 10.1056/NEJMoa1505489.

Davis TL, Walker JR, Campagna-Slater V, Finerty PJ, Paramanathan R, Bernstein G, MacKenzie F, Tempel W, Ouyang H, Lee WH, Eisenmesser EZ, and Dhe-Paganon S (2010) Structural and biochemical characterization of the human cyclophilin family of peptidyl-prolyl isomerases. PLoS Biol 8: e1000439. DOI: 10.1371/journal.pbio.1000439. 
Di Lisa F, Canton M, Carpi A, Kaludercic N, Menabò R, Menazza S, and Semenzato M (2011) Mitochondrial injury and protection in ischemic pre- and postconditioning. Antioxid Redox Signal 14: 881-891. DOI: 10.1089/ars.2010.3375.

Dube H, Selwood D, Malouitre S, Capano M, Simone MI, and Crompton M (2012) A mitochondrial-targeted cyclosporin A with high binding affinity for cyclophilin D yields improved cytoprotection of cardiomyocytes. Biochem J 441: 901-907. DOI: 10.1042/BJ20111301.

Dunyak BM and Gestwicki JE (2016) Peptidyl-Proline Isomerases (PPIases): Targets for Natural Products and Natural Product-Inspired Compounds. J Med Chem 59: 9622-9644. DOI: 10.1021/acs.jmedchem.6b00411.

Elimadi A, Morin D, Albengres E, Chauvet-Monges AM, Allain V, Crevat A, and Tillement JP (1997) Differential effects of zidovudine and zidovudine triphosphate on mitochondrial permeability transition and oxidative phosphorylation. Brit J Pharmacol 121: 1295-300. DOI: 10.1038/sj.bjp.0701276.

Fontaine E, Ichas F, and Bernardi P (1998) A ubiquinone-binding site regulates the mitochondrial permeability transition pore. J Biol Chem 273: 25734-25740. DOI: 10.1074/jbc.273.40.25734.

Gutiérrez-Aguilar M and Baines CP (2015) Structural mechanisms of cyclophilin Ddependent control of the mitochondrial permeability transition pore. Biochim Biophys Acta 1850: 2041-2047. DOI: 10.1016/j.bbagen.2014.11.009.

Halestrap AP, Clarke SJ, and Javadov SA (2004) Mitochondrial permeability transition pore opening during myocardial reperfusion--a target for cardioprotection. Cardiovasc Res 61: 372-385. DOI: 10.1016/S0008-6363(03)00533-9.

Halestrap AP (2010) A pore way to die: the role of mitochondria in reperfusion injury and cardioprotection. Biochem Soc Trans 38: 841-860. DOI: 10.1042/BST0380841.

Halestrap AP and Richardson AP (2015) The mitochondrial permeability transition: a current perspective on its identity and role in ischaemia/reperfusion injury. J Mol Cell Cardiol. 78: 129-141. doi: 10.1016/j.yjmcc.2014.08.018. 
Hausenloy DJ, Barrabes JA, Bøtker HE, Davidson SM, Di Lisa F, Downey J, Engstrom T, Ferdinandy P, Carbrera-Fuentes HA Heusch G, Ibanez B, Iliodromitis EK, Inserte J, Jennings R, Kalia N, Kharbanda R, Lecour S, Marber M, Miura T, Ovize M, Perez-Pinzon MA, Piper HM, Przyklenk K, Schmidt MR, Redington A, Ruiz-Meana M, Vilahur G, Vinten-Johansen J, Yellon DM, and Garcia-Dorado D (2016) Ischaemic conditioning and targeting reperfusion injury: a 30 year voyage of discovery. Basic Res Cardiol 111: 70. DOI: $10.1007 / \mathrm{s} 00395-016-0588-8$.

Heusch G (2015) CIRCUS: a kiss of death for cardioprotection? Cardiovasc Res 108: 215216. DOI: $10.1093 / \mathrm{cvr} / \mathrm{cvv} 225$

Ikeda G, Matoba T, Nakano Y, Nagaoka K, Ishikita A, Nakano K, Funamoto D, Sunagawa K, and Egashira K (2016) Nanoparticle-Mediated Targeting of Cyclosporine A Enhances Cardioprotection Against Ischemia-Reperfusion Injury Through Inhibition of Mitochondrial Permeability Transition Pore Opening. Sci Rep 6: 20467. DOI: $10.1038 /$ srep20467.

Malouitre S, Dube H, Selwood D, and Crompton M (2009) Mitochondrial targeting of cyclosporin A enables selective inhibition of cyclophilin-D and enhanced cytoprotection after glucose and oxygen deprivation. Biochem J 425:137-148. DOI: 10.1042/BJ20090332.

Mewton N, Croisille P, Gahide G, Rioufol G, Bonnefoy E, Sanchez I, Cung TT, Sportouch C, Angoulvant D, Finet G, André-Fouët X, Derumeaux G, Piot C, Vernhet H, Revel D, and Ovize M. (2010). Effect of cyclosporine on left ventricular remodeling after reperfused myocardial infarction. J Am Coll Cardiol 55:1200-1205. DOI: 10.1016/j.jacc.2009.10.052.

Monassier L, Ayme-Dietrich E, Aubertin-Kirch G, and Pathak A (2016) Targeting myocardial reperfusion injuries with cyclosporine in the CIRCUS Trial - pharmacological reasons for failure. Fundam Clin Pharmacol 30:191-193. DOI: 10.1111/fcp.12177.

Morin D, Assaly R, Paradis S, and Berdeaux A (2009) Inhibition of mitochondrial membrane permeability as a putative pharmacological target for cardioprotection. Curr Med Chem 16: 4382-4398. DOI: 10.2174/092986709789712871.

Nevers Q, Ruiz I, Ahnou N, Donati F, Brillet R, Softic L, Chazal M, Jouvenet N, Fourati S, Baudesson C, Bruscella P, Gelin M, Guichou JF, Pawlotsky JM, and Ahmed-Belkacem A (2018) Characterization of the Anti-Hepatitis C Virus Activity of New Nonpeptidic Small- 
Molecule Cyclophilin Inhibitors with the Potential for Broad Anti-Flaviviridae Activity. Antimicrob Agents Chemother 62: e00126-18. DOI: 10.1128/AAC.00126-18.

Obame FN, Plin-Mercier C, Assaly R, Zini R, Dubois-Randé JL, Berdeaux A, and Morin D (2008) Cardioprotective effect of morphine and a blocker of glycogen synthase kinase 3 beta, SB216763 [3-(2,4-dichlorophenyl)-4(1-methyl-1H-indol-3-yl)-1H-pyrrole-2,5-dione], via inhibition of the mitochondrial permeability transition pore. J Pharmacol Exp Ther 326: 252-258. DOI: 10.1124 /jpet.108.138008.

Ottani F, Latini R, Staszewsky L, La Vecchia L, Locuratolo N, Sicuro M, Masson S, Barlera S, Milani V, Lombardi M, Costalunga A, Mollichelli N, Santarelli A, De Cesare N, Sganzerla P, Boi A, Maggioni AP, and Limbruno U (2016) CYCLE Investigators. Cyclosporine A in Reperfused Myocardial Infarction: The Multicenter, Controlled, OpenLabel CYCLE Trial. J Am Coll Cardiol 67: 365-374. DOI: 10.1016/j.jacc.2015.10.081.

Panel M, Ghaleh B, and Morin D (2017) Ca2+ ionophores are not suitable for inducing mPTP opening in murine isolated adult cardiac myocytes. Sci Rep 7: 4283. DOI: 10.1038/s41598017-04618-4.

Panel M, Ruiz I, Brillet R, Lafdil F, Teixeira-Clerc F, Nguyen T, Calderaro J, Gelin M, Allemand F, Guichou JF, Ghaleh B, Ahmed-Belkacem A, Morin D, and Pawlotsky JM (2019) Small-molecule cyclophilin inhibitors block mitochondrial permeability transition pore opening and protect from hepatic ischemia-reperfusion injury. Gastroenterology 157: 1368-1382. DOI: 10.1053/j.gastro.2019.07.026.

Petronilli V, Miotto G, Canton M, Brini M, Colonna R, Bernardi P, and Di Lisa F (1999) Transient and long-lasting openings of the mitochondrial permeability transition pore can be monitored directly in intact cells by changes in mitochondrial calcein fluorescence. Biophys J 76: 725-734. DOI: 10.1016/S0006-3495(99)77239-5.

Petronilli V, Penzo D, Scorrano L, Bernardi P, and Di Lisa F (2001) The mitochondrial permeability transition, release of cytochrome $\mathrm{c}$ and cell death. Correlation with the duration of pore openings in situ. J Biol Chem 276:12030-12034. DOI: 10.1074/jbc.M010604200.

Piot C, Croisille P, Staat P, Thibault H, Rioufol G, Mewton N, Elbelghiti R, Cung TT, Bonnefoy E, Angoulvant D, Macia C, Raczka F, Sportouch C, Gahide G, Finet G, André- 
Fouët X, Revel D, Kirkorian G, Monassier JP, Derumeaux G, and Ovize M (2008) Effect of cyclosporine on reperfusion injury in acute myocardial infarction. New Engl J Med 359: 473-481. DOI: 10.1056/NEJMoa071142.

Schaller S, Paradis S, Ngoh GA, Assaly R, Buisson B, Drouot C, Ostuni MA, Lacapere JJ, Bassissi F, Bordet T, Berdeaux A, Jones SP, Morin D, and Pruss RM (2010) TRO40303, a new cardioprotective compound, inhibits mitochondrial permeability transition. $J$ Pharmacol Exp Ther 333: 696-706. DOI: 10.1124/jpet.110.167486.

Silva FS, Simoes RF, Couto R, and Oliveira PJ (2016) Targeting Mitochondria in Cardiovascular Diseases. Curr Pharm Des 22: 5698-5717. DOI: $10.2174 / 1381612822666160822150243$

Townsend PA, Davidson SM, Clarke SJ, Khaliulin I, Knight RA, Stephanou A, Latchman DS, Carroll CJ, Scarabelli TM, and Halestrap AP (2007) Urocortin prevents mitochondrial permeability transition in response to reperfusion injury indirectly by reducing oxidative stress. Am J Physiol Heart Circ Physiol 293: H928-H938. DOI: 10.1152/ajpheart.01135.2006.

Trankle C, Thurber CJ, Toldo S, and Abbate A (2016) Mitochondrial Membrane Permeability Inhibitors in Acute Myocardial Infarction: Still Awaiting Translation. JACC: Basic Trans Sci 1: 524-535. DOI: 10.1016/j.jacbts.2016.06.012.

Wang P and Heitman J (2005) The cyclophilins. Genome Biol 6: 226. DOI: 10.1186/gb-20056-7-226.

Yellon DM and Hausenloy DJ (2007) Myocardial reperfusion injury. N Engl J Med 357: 1121-1135. DOI: 10.1056/NEJMra071667. 


\section{Footnotes}

Funding: This work was supported by the French Ministry for Higher Education and Research ( $\mathrm{N}^{\circ}$ 2014-140 to M. Panel) and The National Agency for Research on AIDS and Viral Hepatitis (to I. Ruiz).

Conflict of interests: Inserm Transfert is the owner of patent EP 09306294.1 covering the family of cyclophilin inhibitors including the C31 compound, for which Abdelhakim AhmedBelkacem, Jean-François Guichou and Jean-Michel Pawlotsky are inventors. All other authors declare no competing financial interests.

\section{Reprint requests should be addressed to:}

Didier MORIN, PhD

INSERM U955, Team Ghaleh, Faculté de Médecine,

8 rue du général Sarrail, 94000, Créteil, France.

E-mail : didier.morin@inserm.fr 


\section{Figure Legends}

Figure. 1: C31 prevents calcium-induced swelling in isolated cardiac and liver mitochondria.

Representative experiment showing the inhibition of swelling by increasing concentrations of C31 $(0.1-10 \mu \mathrm{M})$ or CsA $(2 \mu \mathrm{M})$ in energized rat cardiac mitochondria. Swelling was induced by addition of $250 \mu \mathrm{M} \mathrm{Ca}^{2+}$. $\mathrm{IC}_{50}$ were further calculated from the slopes of the curves

\section{Figure. 2: C31 increases calcium retention capacity in cardiac mitochondria.}

Energized rat cardiac mitochondria were challenged with successive $\mathrm{Ca}^{2+}$ quanta $(10 \mu \mathrm{M})$ until the load reached a threshold at which $\mathrm{Ca}^{2+}$ is released through $\mathrm{mPTP}$. Then, $\mathrm{Ca}^{2+}$ retention capacity (CRC) was determined. Typical experiment (a) and bar graph (b) showing that treatment with increasing concentrations of $\mathrm{C} 31$ allowed mitochondria to sustain higher $\mathrm{Ca}^{2+}$ amount than CsA. In the bar graph (b), each value is the mean \pm SEM of at least 4 independent experiments (different mitochondrial preparations) performed in duplicate. ${ }^{*} \mathrm{p}<0.05$ vs control (no drug added); \# $\mathrm{p}<0.05$ vs CsA. $\mathbf{c}$ and $\mathbf{d}$ : CRC was evaluated in cardiac mitochondria isolated from wild-type (c) or Ppif ${ }^{/-}$mice (c and d) in the presence of CsA $(1 \mu \mathrm{M})$ or $\mathrm{C} 31(100 \mu \mathrm{M})$. In the bar graph $(\mathbf{c})$, each value represents the mean \pm SEM of at least 4 independent experiments (different mitochondrial preparations) performed in duplicate. Difference among groups was assessed by one-way ANOVA followed by Tukey's multiple comparison test. ${ }^{*} \mathrm{p}<0.05$ vs Control (no drug added); $\# \mathrm{p}<0.05$ vs CsA

AU: arbitrary units 


\section{Figure 3: C31 inhibits A23187-induced mPTP opening in H9C2 cells.}

a: Experimental procedure: $\mathrm{H} 9 \mathrm{C} 2$ cells were labeled with calcein-AM in the presence of $\mathrm{CoCl}_{2}$ for $30 \mathrm{~min}$ and then placed in a thermostatic chamber for fluorescence imaging. After 5 min of incubation, A23187 (A23, $50 \mathrm{nM})$ was added to the medium to induce mPTP opening and calcein fluorescence was monitored until $30 \mathrm{~min}$. When used, C31 or CsA were incubated 20 min prior to A23187 addition. For each curve three experiments were averaged. b: Inhibition of mPTP opening by $\mathrm{CsA}$ and $\mathrm{C} 31$ : kinetics of calcein fluorescence over reoxygenation time. c: Typical experiment showing the change of calcein fluorescence in the absence (control) or in the presence CsA or C31.

Figure. 4: C31 inhibits mPTP opening and cell death in mouse isolated cardiac myocytes during hypoxia-reoxygenation.

a: Experimental procedure: mouse cardiomyocytes were co-labeled with the association calcein-AM- $\mathrm{CoCl}_{2}$ and propidium iodide (PI) to assess mPTP opening and cell death, respectively. Electrically paced cells were subjected to 45 min hypoxia $\left(1-2 \% \mathrm{O}_{2}, 20 \mathrm{mM} 2-\right.$ deoxyglucose) followed by reoxygenation $\left(21 \% \mathrm{O}_{2}, 5.5 \mathrm{mM}\right.$ glucose $)$ and were monitored during the whole procedure. C31 $(100 \mu \mathrm{M})$ or CsA $(2 \mu \mathrm{M})$ was added 15 min before reoxygenation and maintained during the first $10 \mathrm{~min}$ of reoxygenation. b: Inhibition of mPTP opening by CsA and C31. Left curves: kinetics of calcein fluorescence over reoxygenation time. Right table: average time for mPTP opening $\left(t_{m P T P 50}\right)$. Each curve represents the mean \pm SEM of 5 experiments performed with 5 different cell preparations. Difference between groups was assessed by one-way ANOVA followed by Tukey's multiple comparison test. ${ }^{*} \mathrm{p}<0.05$ vs control. c: Inhibition of cell death by CsA and C31 during reoxygenation monitored by the appearance of propidium iodide (PI) fluorescence. Each curve represents the mean \pm SEM of 5 experiments performed with 5 different cell 
preparations. Difference between groups was assessed by one-way ANOVA followed by Tukey's multiple comparison test. ${ }^{*} \mathrm{p}<0.05$ vs control. d: Typical experiment showing the change of calcein (green) and propidium iodide (red) fluorescence during reoxygenation time in the absence (control) or in the presence of C31

\section{Figure. 5: Effect of $\mathrm{C} 31$ and $\mathrm{CsA}$ on mitochondrial calcium retention capacity following}

\section{Langendorff perfusion of mouse hearts.}

Wild type mouse hearts were cannulated and retrogradely perfused through the aorta. Perfusion pressure was set at $120 \mathrm{mmHg}$ to ensure coronary perfusion. Hearts received vehicle (control), C31 $(100 \mu \mathrm{M})$ or CsA $(2$ and $10 \mu \mathrm{M})$ as a 20 min perfusion. Then mitochondria were isolated and $\mathrm{Ca}^{2+}$ retention capacity (CRC) was evaluated in the absence (hatched bars) or in the presence of $1 \mu \mathrm{M}$ CsA in the incubation medium as a control for maximal CypD-dependent mPTP inhibition (empty bars). CRC (hatched bars, without CsA) were compared by means of a non-parametric test Kruskall-Wallis multiple comparison followed by Dunnett's post hoc test. ${ }^{*} \mathrm{p}<0.05$ vs control value. To analyze the effect of CsA addition in the incubation medium, a 2-way ANOVA with paired values (CRC and CRC + CsA), followed by Fisher's LSD test was used. \#p $<0.05$ vs respective CRC.

Each CRC value is the mean \pm SEM of 4-6 independent experiments (4-6 hearts).

Figure. 6 Effect of in vivo administration of C31 on mitochondrial calcium retention capacity.

Mice were infused with increasing doses of C31 or $20 \mathrm{mg} / \mathrm{kg}$ CsA for $3 \mathrm{~min}$. Two min after the end of infusion, cardiac and liver mitochondria were isolated and mitochondrial $\mathrm{Ca}^{2+}$ retention capacity (CRC) was assessed. Each CRC value is the mean \pm SEM of at least 4 independent experiments (4 animals). Difference among groups was assessed by one-way 
ANOVA followed by Tukey's multiple comparison test. ${ }^{*} \mathrm{p}<0.05$ vs vehicle $(\mathrm{VEH}) ; \# \mathrm{p}<0.05$ vs CsA

Figure. 7 Peptidylpropyl isomerase activity (PPiase) in cytosolic and mitochondrial fractions isolated from mouse heart and liver.

a: Typical curves showing PPiase activity monitored by the release of p-nitroanilide. Arrow: addition of N-Succinyl-Ala-Ala-Pro-Phe-p-nitroanilide.

b and c: Each Bar graph represents the mean \pm SEM of six independent experiments (6 different mitochondrial or cytosolic preparations). Results are expressed as the maximal rate value of p-nitroanilide release. Unpaired Student's t-test

NS: not statistically significant 
Fig. 1

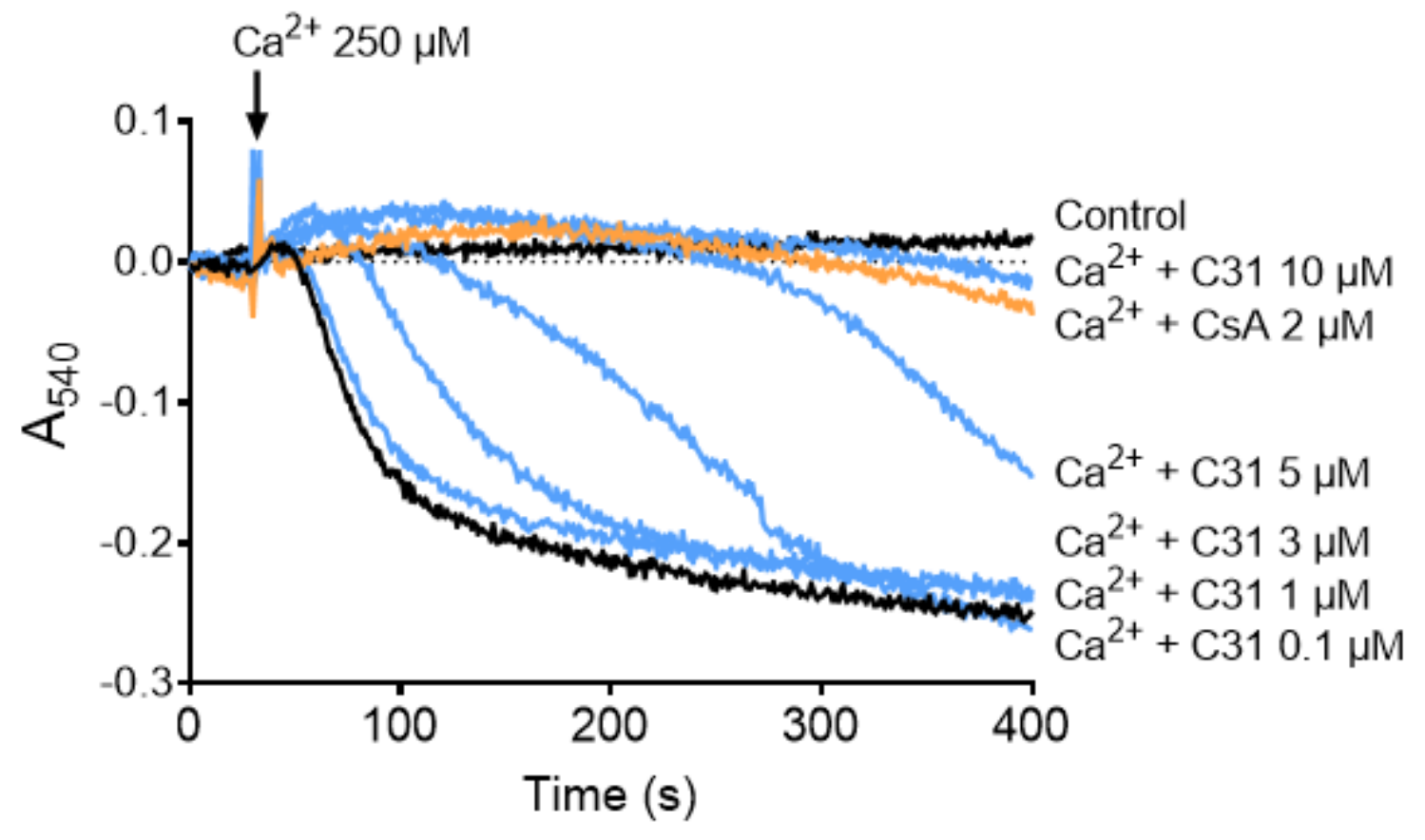


Fig. 2

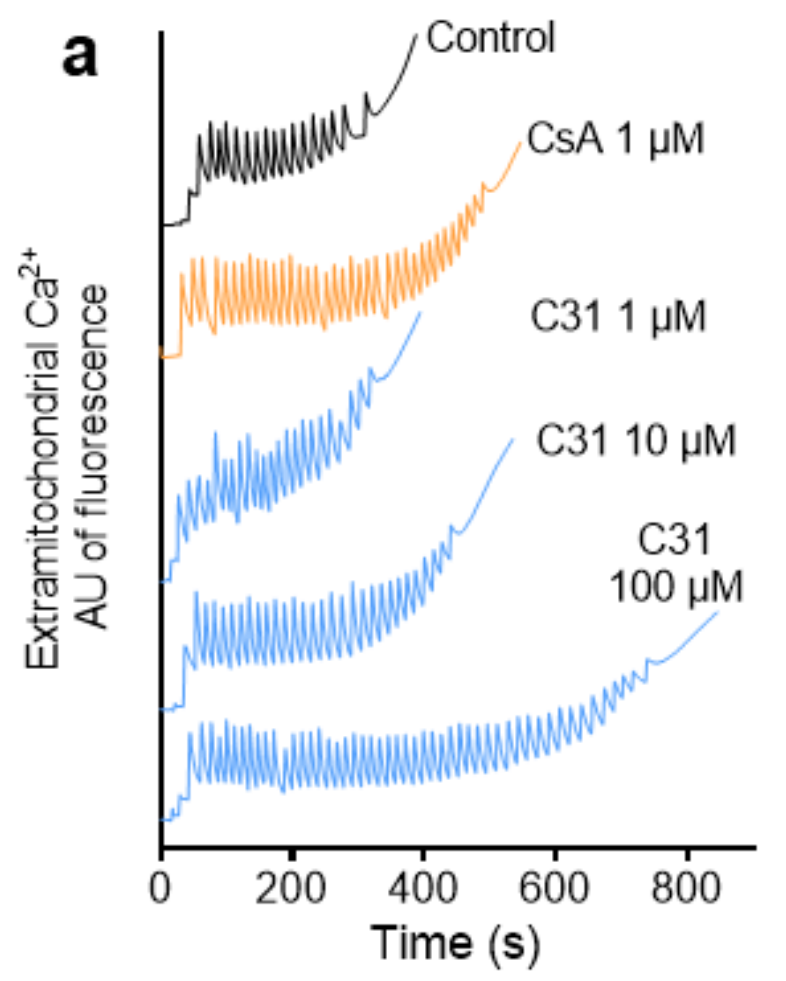

b

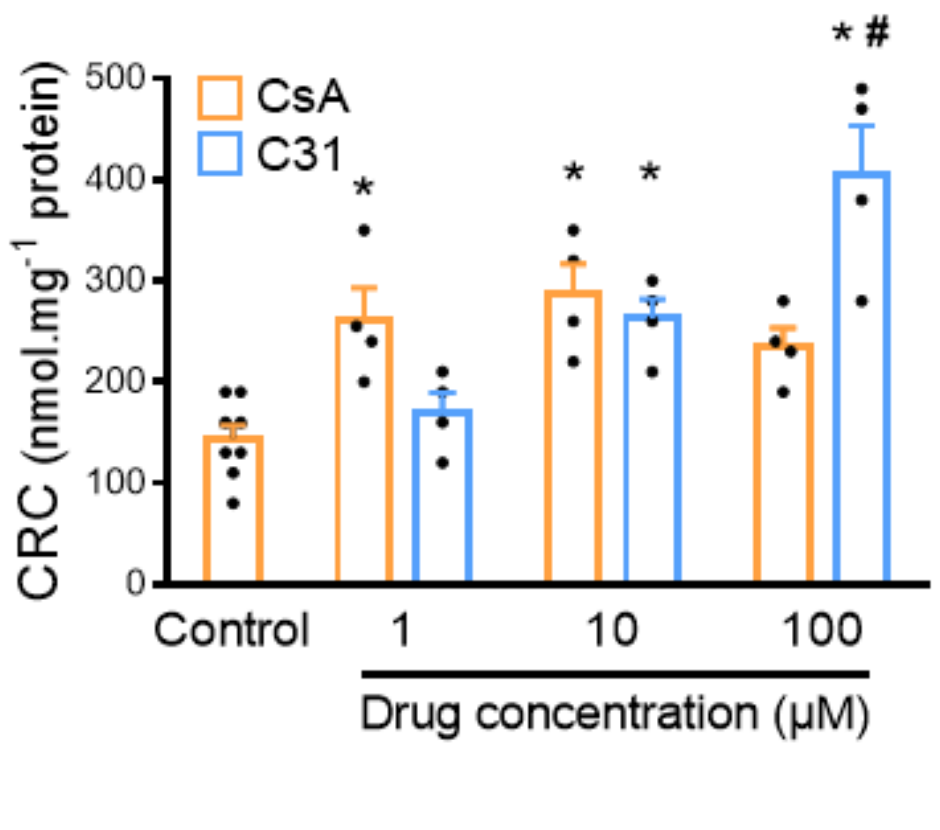

C
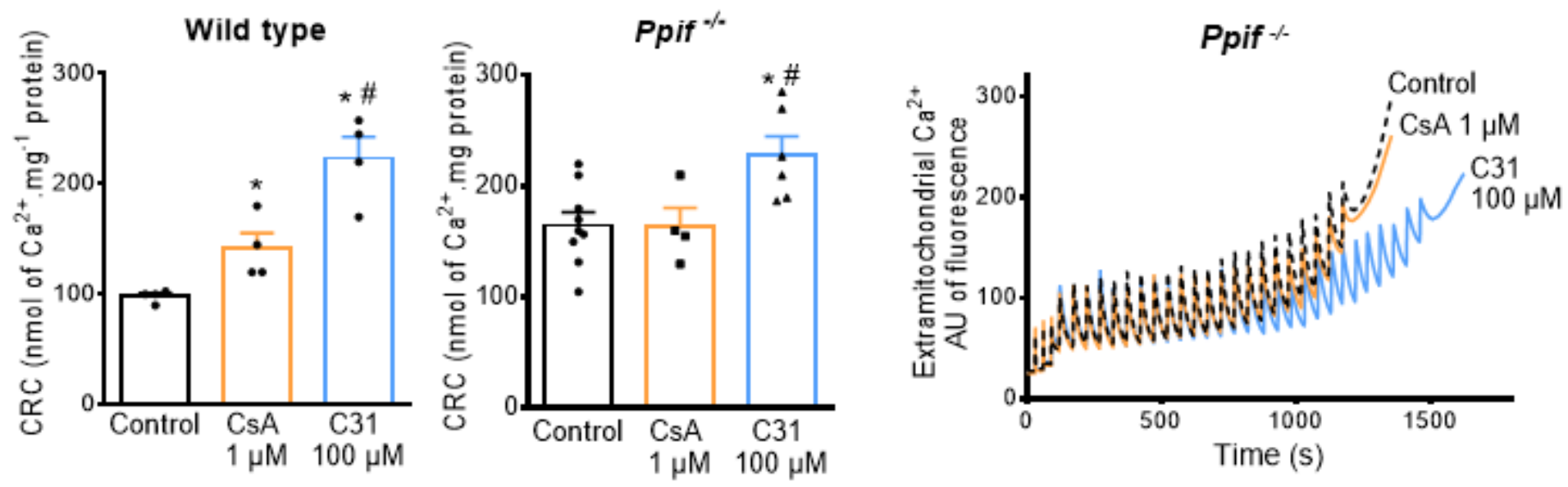
Fig. 3
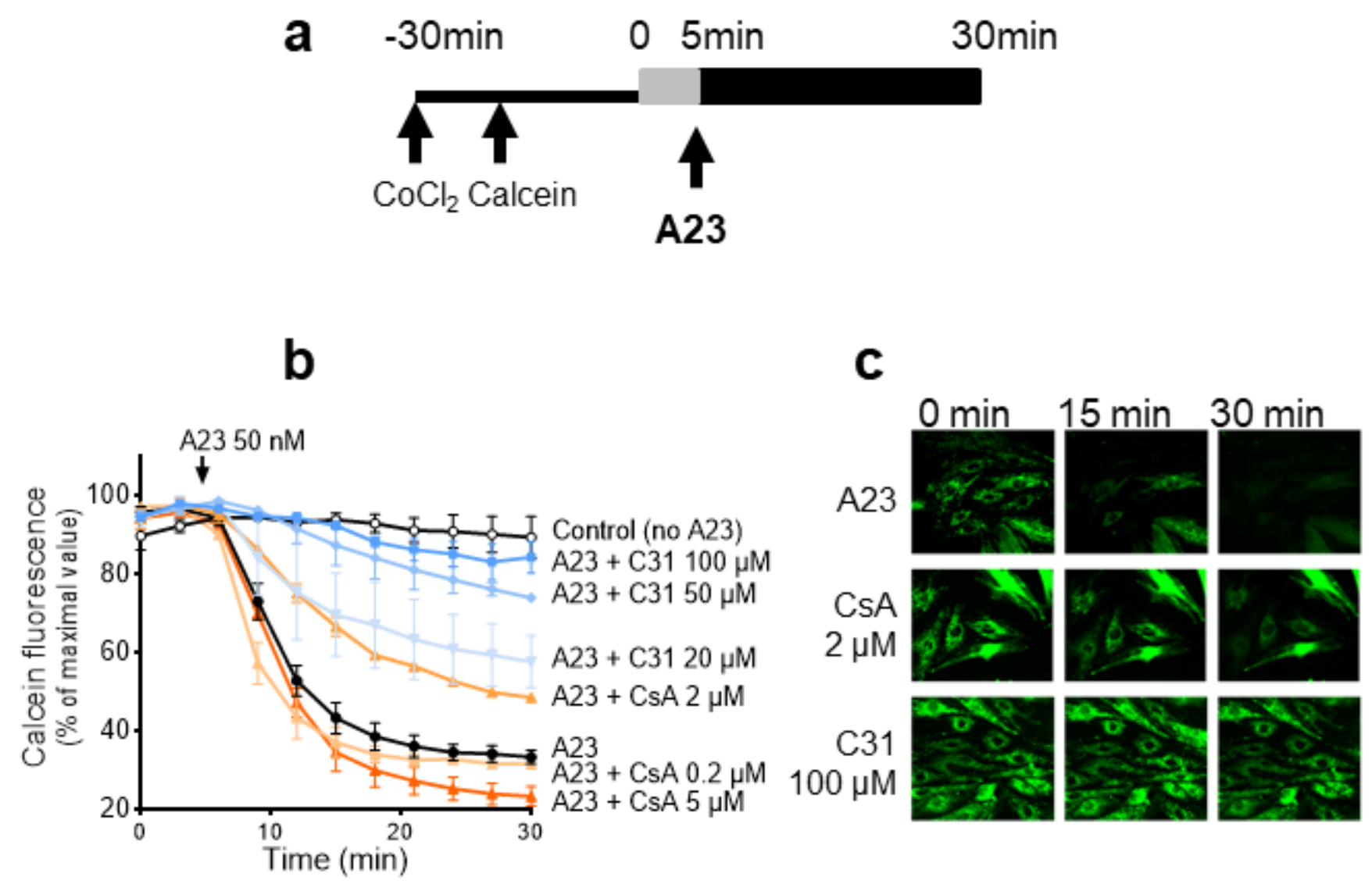
Fig. 4

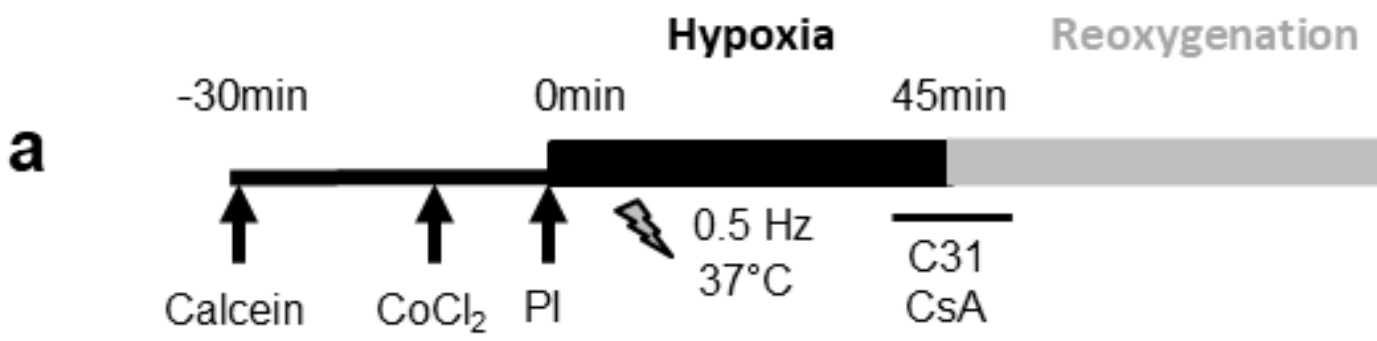

b mPTP opening
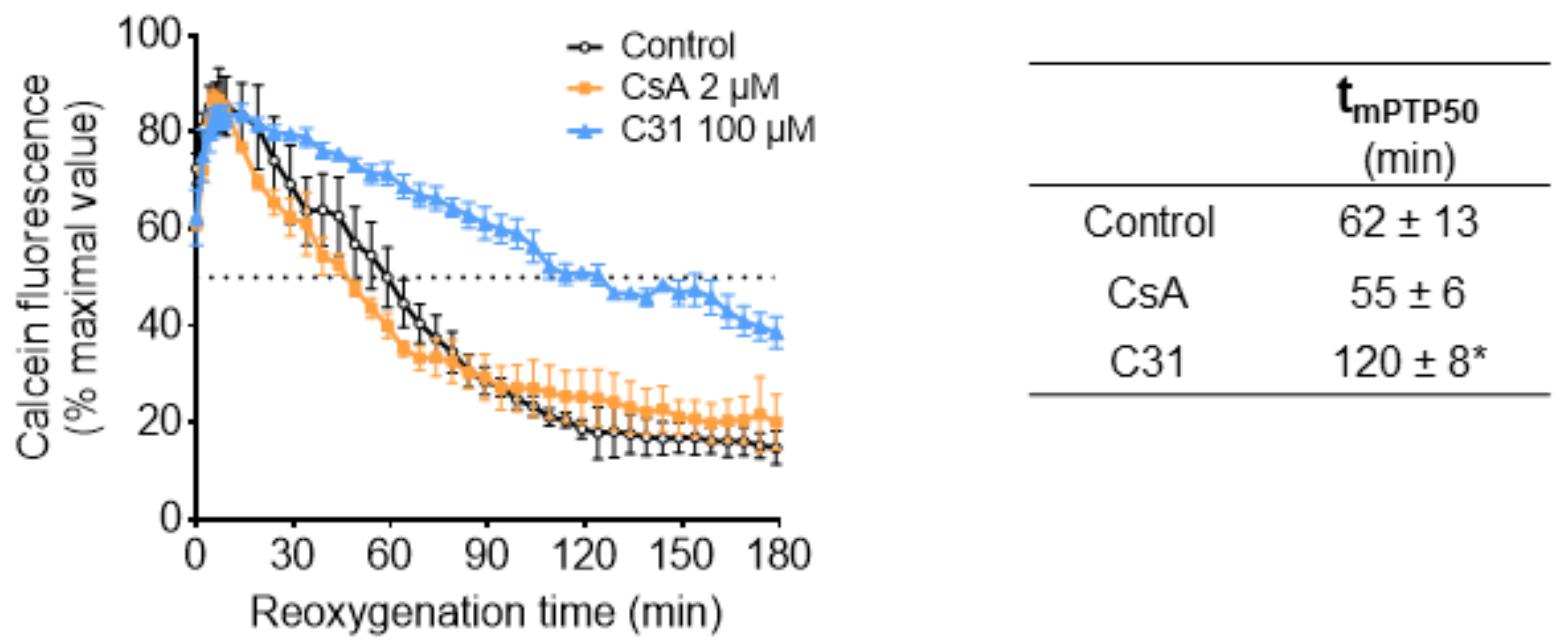
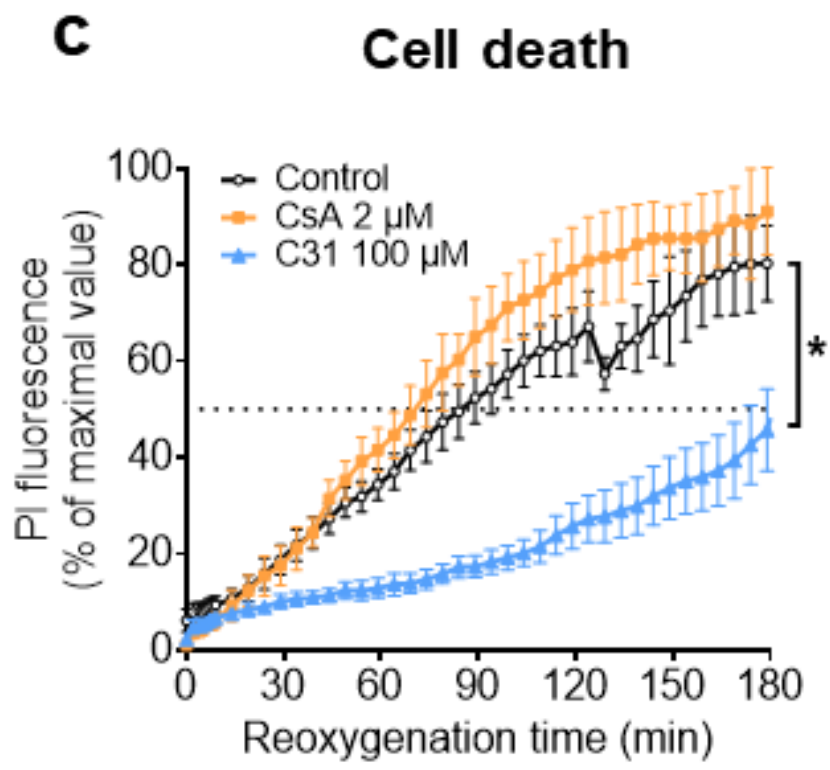

Reoxygenation time (min)

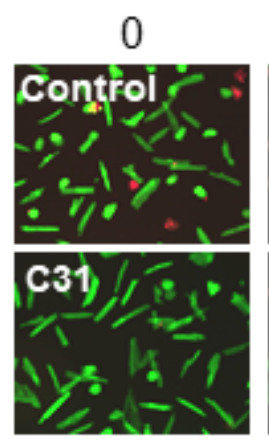

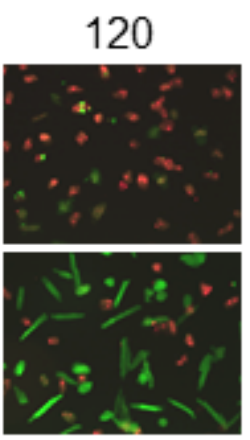


Fig. 5

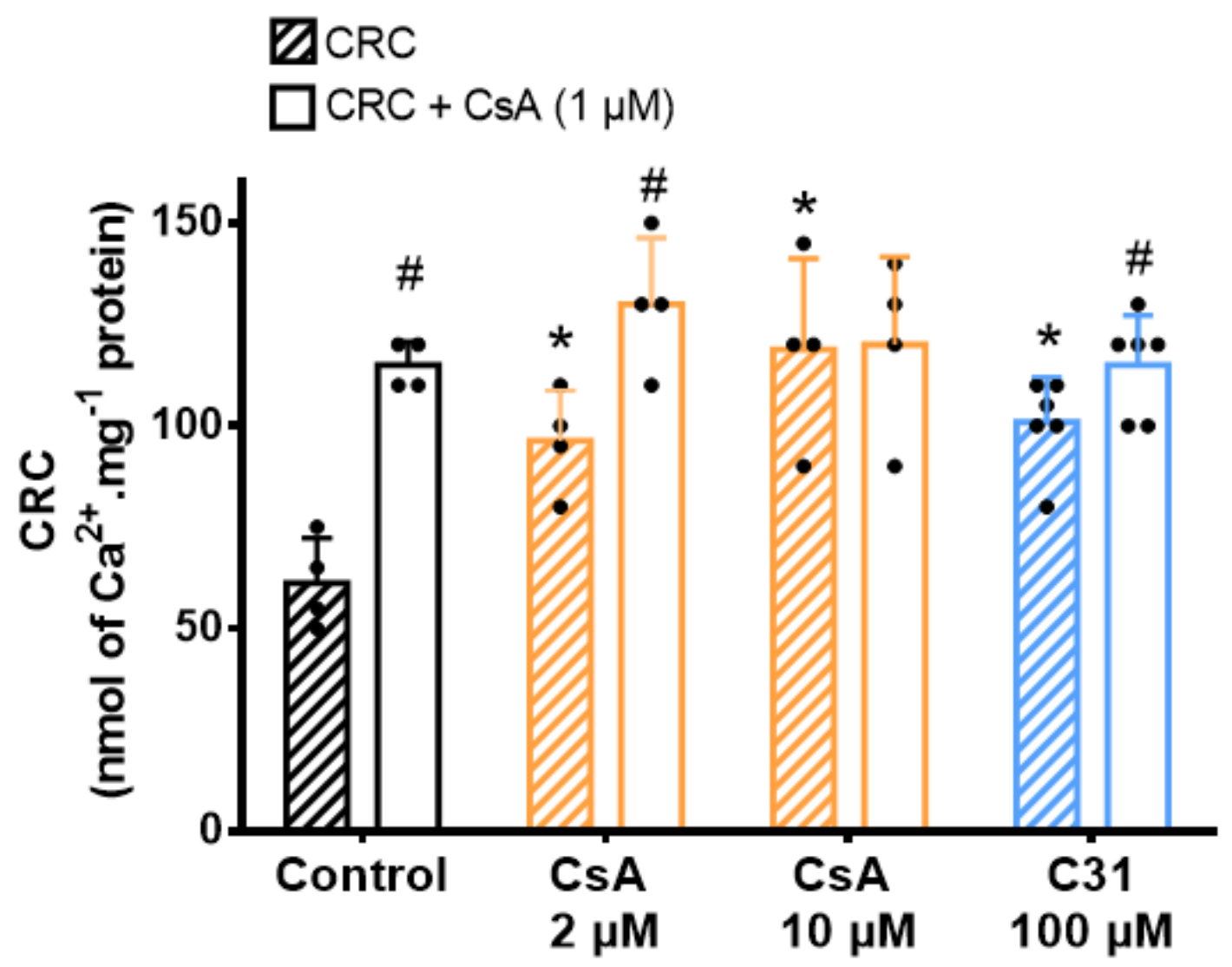


Fig. 6
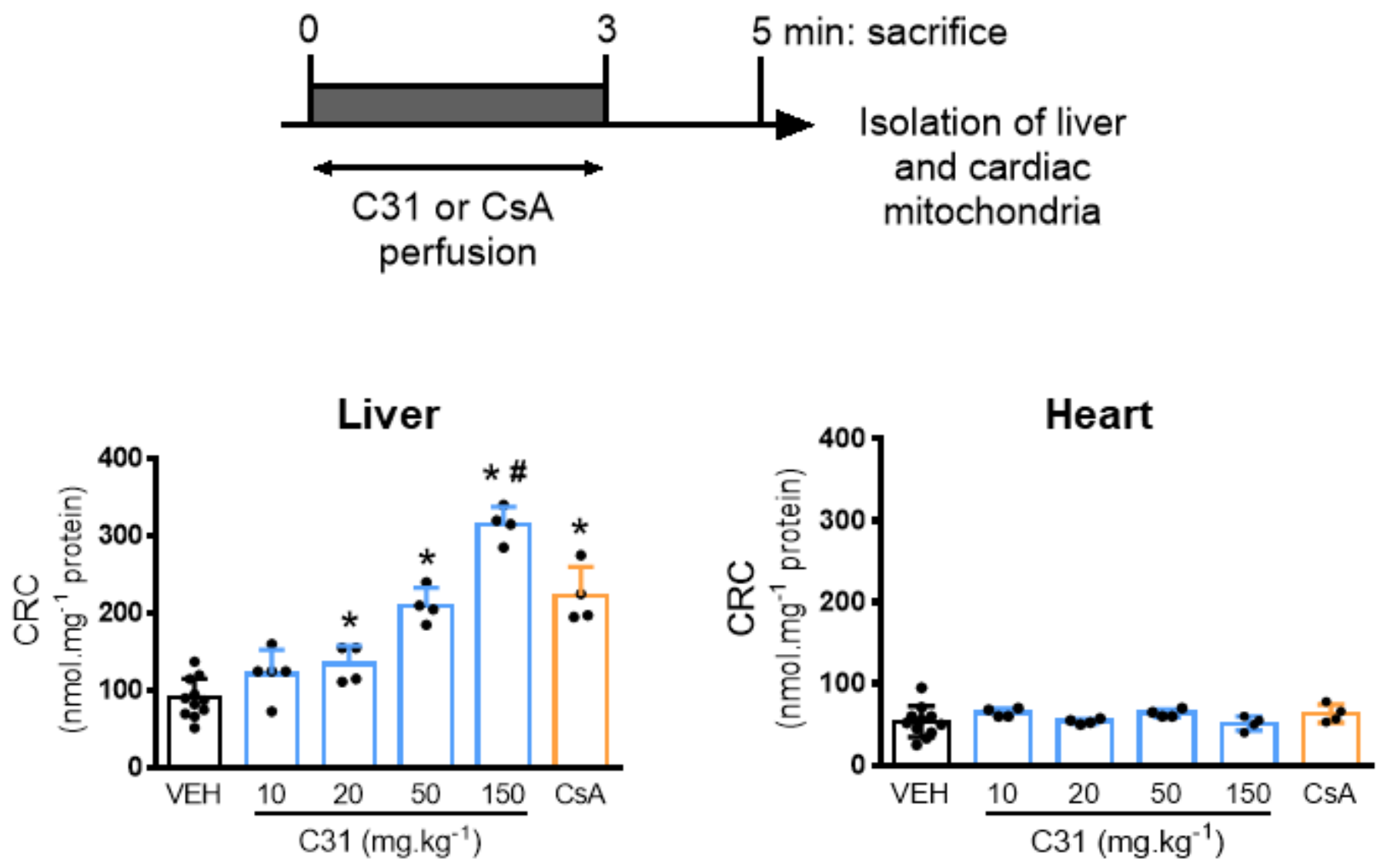
Fig. 7
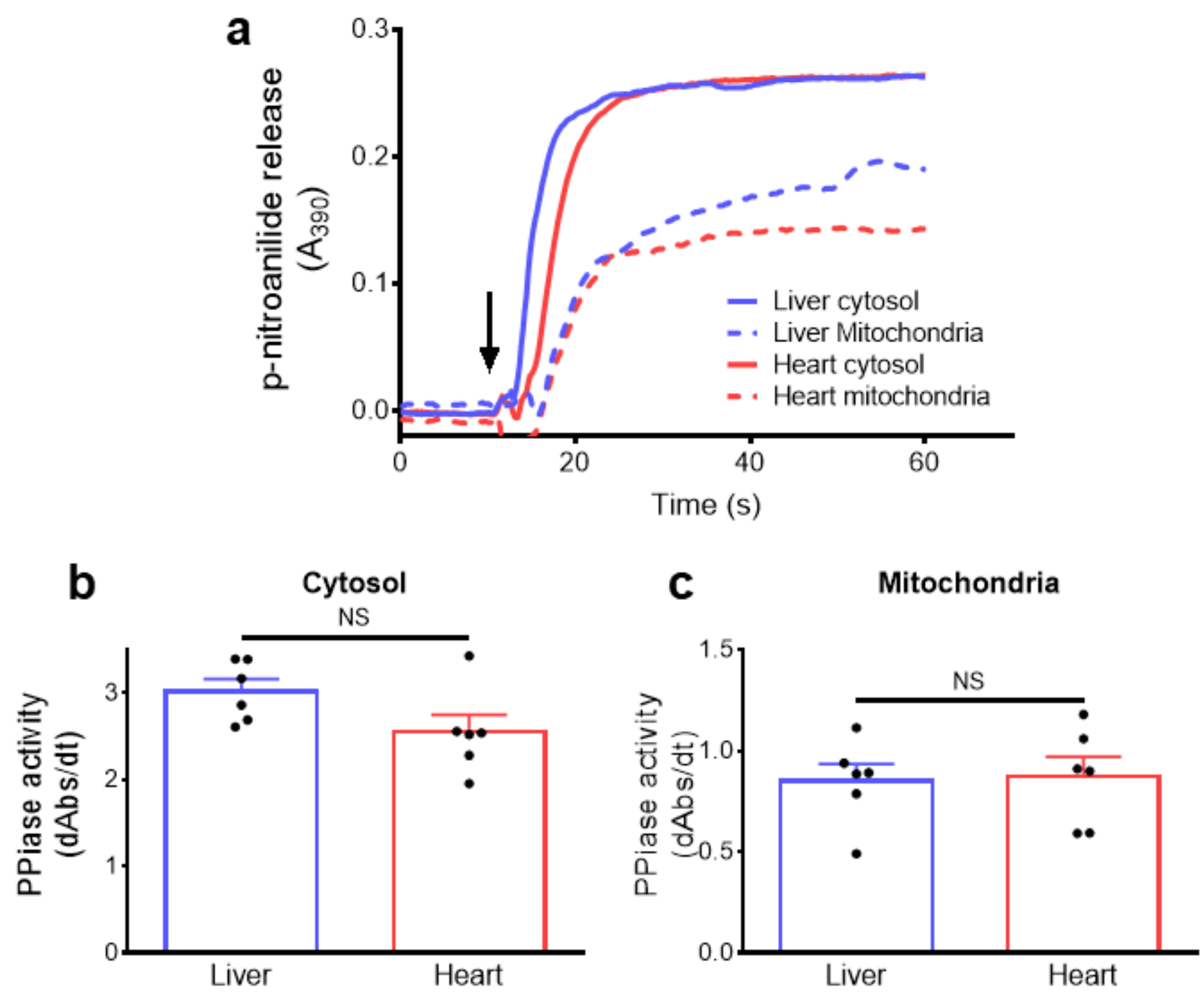